ИССЛЕДОВАТЕЛЬСКАЯ СТАТЬЯ

https://doi.org/10.17059/ekon.reg.2021-3-12

УДК 314.4

\author{
С. Г. Шульгин ${ }^{a)}$, Ю. В. Зинькина ${ }^{\text {б) }}$ \\ а, 6) Российская академия народного хозяйства и государственной службы при Президенте РФ, \\ Москва, Российская Федерация, \\ 6) Московский государственный университет имени М. В. Ломоносова, Москва, Российская Федерация, \\ a) https://orcid.org/0000-0003-1091-7157, e-mail:sergey@shulgin.ru \\ 6) https://orcid.org/0000-0003-0524-2140
}

\title{
Оценка человеческого капитала в макрорегионах России
}

Количественные оценки человеческого капитала важны как для понимания текущего положения дел в обществе, так и для проведения эффективной социально-экономической политики. В данной работе мы используем новый подход к оценке человеческого капитала - индикатор человеческой жизни, который учитывает неравенство в продолжительности жизни. Разработанный ООН индекс человеческого развития не учитывает, что при одинаковой или близкой ожидаемой продолжительности жизни страны могут иметь значительное внутреннее неравенство. Индикатор человеческой жизни, напротив, выявляет подобное неравенство - этот показатель отражает уровень благополучия в терминах лет жизни (аналогично показателю ожидаемой продолжительности жизни), но при этом учитывает уровень неравенства в продолжительности жизни. Расчеты мы проводим с использованием статистических данных о смертности на уровне федеральных округов. В статье сравниваются оценки уровня человеческого развития для федеральных округов РФ по двум методикам - индексу человеческого развития и индикатору человеческой жизни. Сопоставление значений индексов двух регионов выявляет проблему - высокое место в рейтинге индекса человеческого развития может быть обеспечено, к примеру, высоким ВРП, который может и не трансформироваться в улучшение качества жизни для большинства населения. Такова ситуация в Дальневосточном ФО. Благополучные по индикатору человеческой жизни регионы концентрируются в европейской части России и СКФО. Требует внимания федеральных и региональных властей ситуация в большинстве регионов Сибири и Дальнего Востока, где сложилось очень высокое неравенство по ожидаемой продолжительности жизни. Полученные результаты предлагают новый взгляд на оценку успешности развития регионов и могут быть использованы при оценке влияния проводимой социально-экономической политики и реформ системы здравоохранения на качество жизни населения регионов. Представляется возможным использовать данный подход и для сопоставления межрегиональных показателей развития человеческого капитала, поскольку он позволяет корректно сравнивать регионы друг с другом и ежегодно отслеживать изменения в качестве жизни населения региона в динамике.

Ключевые слова: человеческий капитал, индекс человеческого развития, индикатор человеческой жизни, ожидаемая продолжительность жизни, таблицы смертности, уровень образования, состояние здоровья, неравенство в смертности, Россия, федеральные округа РФ, регионы РФ

\section{Благодарность}

Статья подготовлена в рамках гранта, предоставленного Министерством науки и высшего образования Российской Федерации (№ соглашения о предоставлении гранта: 075-15-2020-908).

Для цитирования: Шульгин С. Г., Зинькина Ю. В. Оценка человеческого капитала в макрорегионах России // Экономика региона. 2021. Т. 17, вып. 3. С. 888-901. https://doi.org/10.17059/ekon.reg.2021-3-12.

\footnotetext{
1 ( ) Шульгин С. Г., Зинькина Ю. В., Текст. 2021.
} 


\author{
Sergey G. Shulgin ${ }^{a)}$, Yulia V. Zinkina ${ }^{\text {) }}$ \\ a, b) Russian Presidential Academy of National Economy and Public Administration, Moscow, Russian Federation \\ b) Lomonosov Moscow State University, Moscow, Russian Federation \\ a) https://orcid.org/0000-0003-1091-7157, e-mail: sergey@shulgin.ru \\ b) https://orcid.org/ 0000-0003-0524-2140
}

\title{
Assessment of Human Capital in Russian Macroregions
}

A quantitative assessment of human capital is necessary for both understanding society and implementing effective socio-economic policies. In the present paper, a new approach - the Human Life Indicator (HLI) - was implemented to measure inequality in life expectancy. The Human Development Index (HDI), proposed by the United Nations, does not take into account significant internal inequalities of countries with the same or similar life expectancy. On the contrary, HLI reflects the well-being in terms of years of life, additionally considering the inequality in life expectancy. Presented calculations were based on federal mortality statistics. This study estimated human development of Russian federal districts by comparing HDI and HLI. The analysis revealed that high HDI values, achieved, for example, due to a high gross regional product (GRP) per capita, do not translate into an improvement in the quality of life for the majority of the population. Such situation is observed in the Far Eastern Federal District. The regions that are relatively prosperous in terms of HLI are concentrated in the European part of Russia and the North Caucasus Federal District. Simultaneously, most Siberian and the Far Eastern regions, characterised by high inequality in life expectancy, require the attention of federal and regional authorities. The presented approach to assessing the success of regional development can be used to estimate how the ongoing socio-economic policy and health care reforms influence the quality of life in the regions. This method can also be applied to compare inter-regional indicators of human capital and monitor changes in well-being of the population.

Keywords: human capital, Human Development Index, Human Life Indicator, life expectancy, mortality tables, education level, health status, inequality in mortality, Russia, Russian federal districts, Russian regions

\section{Acknowledgments}

The article was prepared in the framework of a research grant funded by the Ministry of Science and Higher Education of the Russian Federation (grant ID: 075-15-2020-908)

For citation: Shulgin, S. G. \& Zinkina, Yu. V. (2021). Assessment of Human Capital in Russian Macroregions. Ekonomika regiona [Economy of region], 17(3), 888-901, https://doi.org/10.17059/ekon.reg.2021-3-12.

\section{Введение}

Как отмечает В.А. Мау [1, с. 114-115], поиск новых национальных приоритетов, длившийся с самого начала постсоветской истории России, претерпел весьма значимый поворот приблизительно в середине 2000-х гг., когда внимание элиты сместилось с развития различных отраслей хозяйствования на проблематику человеческого капитала - в первую очередь, образования и здравоохранения, развитие которых было поддержано введением соответствующих «приоритетных национальных проектов», одновременно закрепивших значимость этих сфер развития человеческого капитала в политической повестке дня современной России.

Именно образование и здравоохранение являются двумя фундаментальными составляющими человеческого капитала, признаваемыми в качестве таковых практически всеми исследователями человеческого капитала; относительно других составляющих ведется дискуссия. Эта дискуссия чрезвычайно актуальна и имеет большую научно-практическую зна- чимость; как пишет В.А. Мау, «страна, которая сможет сформировать современную эффективную модель развития человеческого капитала, получит огромное преимущество в постиндустриальном мире» [1, с. 115]. Соответственно, значительный интерес представляют новые подходы к оценке человеческого капитала в том числе такие подходы, которые вовлекают в оценку человеческого капитала различные демографические показатели, а также показатели неравенства. В данной работе мы используем новый подход, который основан на вовлечении обоих вышеназванных типов показателей - индикатор человеческой жизни, который учитывает неравенство в продолжительности жизни. Мы показываем потенциал этого подхода, применяя его для анализа уровня развития человеческого капитала в регионах России.

\section{Подходы к оценке человеческого капитала}

Первые идеи о человеческом капитале восходят еще к трудам одного из отцов-основателей экономической теории А. Смита, пола- 
гавшего, что умения и навыки работника являются одним из факторов производства. Однако современная теория человеческого капитала, как принято считать, сформировалась значительно позже, начиная с середины XX в. Традиционно ее становление связывается с именами трех зарубежных экономистов - Дж. Минсера [2], Т. Шульца [3] и Г. Беккера [4]. На начальных этапах своего развития теория человеческого капитала носила почти исключительно экономический характер, рассматривая лишь те инвестиции в человека, которые повышали и улучшали его образование, умения и навыки, пригодные в профессиональном труде - иными словами, человеческий капитал рассматривался лишь как фактор производства.

Новый подход был предложен в 1990 г. Организацией Объединенных Наций, заявившей, что фокусировка исключительно на экономических показателях задает слишком узкий подход к оценке развития человека. В качестве альтернативного и более всеобъемлющего способа измерения человеческого развития был предложен Human Development Index (HDI) - индекс человеческого развития (ИЧР) [5]. Так, в версии отчета ООН в 2019 г. [6] используется методология, в которой уровень человеческого развития концептуализируется через три компонента: здоровье, образование и экономические условия. Эти показатели вычисляются на основе четырех индикаторов на уровне страны: ожидаемая продолжительность жизни при рождении, средние и ожидаемые годы обучения (на основе которых высчитывается единый индекс образования, и именно он входит в вычисление ИЧР) и логарифм валового национального дохода на душу населения (с учетом паритета покупательной способности (ППС), в долларах США).

Однако подход, предложенный ООН, также подвергался разносторонней критике от технических особенностей расчетов до отсутствия консенсуса по относительной важности факторов, влияющих на развитие человека в целом, на концептуальном уровне (обзор критических работ см. в [7, 8]). В частности, ставилось под сомнение наличие связи между ВНП на душу населения и благополучием населения [9-12], отсутствие в индексе других важных аспектов развития $[13,14]$. Все эти работы можно считать составной частью важного научного дискурса последних десятилетий о подходах к измерению уровня развития, уровня человеческого капитала, уровня и качества жизни [15-17].
Одним из важных пунктов критики явилось то, что ни по одному из трех компонентов ИЧР не учитывает внутристрановое (а также отчасти и межстрановое) неравенство, которое может быть весьма значительным и существенно отражаться на реальном уровне человеческого развития различных групп в составе населения страны [18-23]. Так, фиксируя лишь количественные показатели образования, ИЧР не учитывает, что один год школьного обучения в разных странах может иметь сильно различающуюся «стоимость» в плане получаемых учениками знаний и навыков. Об этом наглядно свидетельствуют данные Международной программы по оценке образовательных достижений учащихся (PISA = Programme for International Student Assessment), оценивающей знания и умения применять их на практике среди 15-летних школьников в разных странах мира. Неравенство по доходам также никаким образом не фиксируется в ИЧР. Наконец, при одинаковой или близкой ожидаемой продолжительности жизни страны могут иметь разную ожидаемую продолжительность здоровой жизни и различные возрастные показатели смертности - иными словами, и в этой сфере ИЧР может скрадывать существенные различия между странами и внутреннее неравенство.

\section{Индикатор человеческой жизни: концепция, методология, данные}

Изложенные соображения, в особенности касающиеся неравенства, скрадываемого показателем ожидаемой продолжительности жизни, мотивировали группу исследователей на разработку альтернативного подхода к оценке уровня человеческого развития и благополучия. Индикатор человеческой жизни (ИЧЖ) (Human Life Indicator) [7, 24] - это показатель, отражающий уровень благополучия в терминах лет жизни (аналогично показателю ожидаемой продолжительности жизни), но при этом учитывающий уровень неравенства в продолжительности жизни. Две страны с одинаковой ожидаемой продолжительностью жизни при рождении могут иметь разный ИЧЖ. Страна с меньшим неравенством в продолжительности жизни будет иметь более высокий ИЧЖ. Доступность данных о смертности дает возможность использовать ИЧЖ для межстранового и межрегионального сопоставления уровня благополучия населения, а также сопоставления исторических траекторий развития обществ. Динамика ИЧЖ во времени и его пространственное распределение позво- 
ляют количественно оценивать происходящие социальные экономические и политические процессы.

ИЧЖ строится на таблицах смертности, как и ОПЖ; и ИЧЖ, и ОПЖ могут рассчитываться для регионов и фиксировать межрегиональные различия. Однако ИЧЖ имеет одно важное преимущество по сравнению с ОПЖ он позволяет оценивать не только межрегиональное, но и внутрирегиональное неравенство. Рассмотрим условную ситуацию - два региона с одинаковым показателем ОПЖ, допустим, в 60 лет, могут иметь весьма различную ситуацию в плане неравенства в продолжительности жизни - в одном половина населения доживает до 58 лет, другая до 62 лет, во втором регионе половина населения доживает до 75 лет, другая половина - до 45 лет. Показатель ОПЖ в обоих случаях будет одинаковым - однако совершенно очевидно, что во втором регионе неравенство среди населения намного выше и ситуация явно требует анализа и вмешательства через изменение политики в области здравоохранения, различные социальные программы и т. д. Традиционная методика расчета ОПЖ не позволяет увидеть эти важные различия - и здесь вступает в дело показатель ИЧЖ, который подобные различия выявляет.

Методология оценки показателя индикатора человеческой жизни представлена в работе Гишланди - Сандерсона - Щербова [7]:

$$
\text { ИЧЖ }=\prod_{i=1}^{N}\left(\text { age }_{i}+a_{i}\right)^{d_{i}},
$$

где $N$ - общее количество интервалов в таблице смертности; age $_{i}+a_{i}-$ среднее число лет которое проживает человек, умирающий в возрастах от age $_{i}$ до age $_{i+1} ; d_{i}$ - доля умерших в возрасте от agei до age $_{i+1}$ от общего числа умерших.

Все данные, используемые в формуле (1), содержатся в таблице смертности, поэтому ИЧЖ можно рассчитывать для любой популяции, для которой достаточно данных для оценок отдельных показателей таблиц смертности.

Формула (1) представляет собой геометрически среднюю продолжительность жизни. Ее можно записать через средневзвешенные значения логарифмов продолжительности жизни (2):

$$
\text { ИЧЖ }=\exp \left(\sum_{i=1}^{N} d_{i} \ln \left(\text { age }_{i}+a_{i}\right)\right) \text {. }
$$

Таким образом, смерти в более ранних возрастах оказывают существенное влияние на значение индикатора человеческой жизни.
Важную роль при оценке ИЧЖ играет уровень младенческой смертности. Данные о младенческой смертности будут учитываться в первом сомножителе (для формулы (1)) или первом слагаемом (для формулы (2)). Это соответствует первой строке таблицы смертности $(i=1)$, описывающей смертность в интервале возрастов от 0 до 1 года, т. е. в формулах (1) и (2) age 1 равен 0, а показатель $a_{1}-$ это оценка средней продолжительности жизни при младенческой смертности.

Для оценки значений показателя $a_{1}$ (если данные не представлены в таблице смертности) мы используем 3-интервальную формулу, предложенную в работе [25], в которой на эмпирических данных таблиц смертности из разных стран (представленных в Human Mortality Database) дается оценка связи показателя младенческой смертности $\left(q_{0}\right)$ с показателем средней длительности жизни при младенческой смертности $\left(a_{0}\right)^{1}$.

\section{Сопоставление оценок уровня человеческого развития согласно ИЧР и индикатору человеческой жизни (на примере федеральных округов РФ)}

В данном разделе мы рассмотрим, насколько различаются оценки уровня человеческого развития для федеральных округов РФ, по методикам по методике ООН и Индикатору человеческой жизни. В таблице 1 и на рисунке 1 приведены оценки индекса человеческого развития (по методике $\mathrm{OOH}$ ).

Детальный анализ отдельных составляющих ИЧР для федеральных округов за 2018 г. приведен в таблице 2 .

В последней строке (COR(ИЧР)) приведены ранговые корреляции за анализируемый год значений отдельных компонент ИЧР (для 8 федеральных округов) с итоговым индексом человеческого развития. Заметим, что компонента отражающая богатство региона (ВНД - валовый национальный доход) в случае федеральных округов в значительной степени определяет положением округа по оценкам человеческого капитала (измеряемого через ИЧР). При этом оценки ВНД на душу населения в регионе (по методологии ООН они должны быть сделаны с учетом паритета покупательной способности) могут в значительной степени быть связаны с рентными доходами и не транслироваться в показатели развития человеческого капитала населения данных регионов. Методология региональных оценок

\footnotetext{
${ }^{1}$ Соответствующих показателю $a_{1}$ в нашем обозначении.
} 
Значения ИЧР по федеральным округам РФ, 1990-2018 гг.

Таблица 1

HDI values by federal districts of the Russian Federation, 1990-2018

Table 1

\begin{tabular}{|c|c|c|c|c|c|c|c|c|c|}
\hline \multirow{2}{*}{ Год } & \multirow{2}{*}{$\begin{array}{c}\text { Значение ИЧР по РФ } \\
\text { Россия }\end{array}$} & \multicolumn{8}{|c|}{ Значения ИЧР по федеральным округам } \\
\hline & & ЦФО & СЗФО & ЮФО & СКФО & ПФО & УрФO & СФО & ДФО \\
\hline 1990 & 0,734 & 0,751 & 0,738 & 0,710 & 0,708 & 0,725 & 0,746 & 0,712 & 0,743 \\
\hline 1991 & 0,730 & 0,746 & 0,734 & 0,705 & 0,704 & 0,721 & 0,741 & 0,708 & 0,738 \\
\hline 1992 & 0,719 & 0,736 & 0,719 & 0,698 & 0,699 & 0,710 & 0,729 & 0,696 & 0,725 \\
\hline 1993 & 0,710 & 0,729 & 0,707 & 0,693 & 0,704 & 0,704 & 0,721 & 0,686 & 0,716 \\
\hline 1994 & 0,702 & 0,718 & 0,700 & 0,687 & 0,701 & 0,695 & 0,712 & 0,676 & 0,710 \\
\hline 1995 & 0,701 & 0,717 & 0,701 & 0,683 & 0,696 & 0,693 & 0,710 & 0,677 & 0,705 \\
\hline 1996 & 0,702 & 0,720 & 0,706 & 0,682 & 0,690 & 0,693 & 0,711 & 0,676 & 0,705 \\
\hline 1997 & 0,704 & 0,722 & 0,711 & 0,682 & 0,688 & 0,694 & 0,716 & 0,678 & 0,710 \\
\hline 1998 & 0,704 & 0,721 & 0,708 & 0,681 & 0,685 & 0,694 & 0,715 & 0,680 & 0,710 \\
\hline 1999 & 0,710 & 0,732 & 0,711 & 0,691 & 0,688 & 0,698 & 0,719 & 0,681 & 0,716 \\
\hline 2000 & 0,721 & 0,746 & 0,719 & 0,698 & 0,699 & 0,707 & 0,732 & 0,691 & 0,721 \\
\hline 2001 & 0,727 & 0,750 & 0,724 & 0,707 & 0,712 & 0,714 & 0,742 & 0,697 & 0,727 \\
\hline 2002 & 0,733 & 0,759 & 0,730 & 0,714 & 0,718 & 0,716 & 0,746 & 0,700 & 0,733 \\
\hline 2003 & 0,740 & 0,768 & 0,735 & 0,720 & 0,727 & 0,723 & 0,754 & 0,706 & 0,737 \\
\hline 2004 & 0,746 & 0,774 & 0,744 & 0,724 & 0,733 & 0,727 & 0,762 & 0,714 & 0,738 \\
\hline 2005 & 0,752 & 0,783 & 0,748 & 0,728 & 0,732 & 0,731 & 0,771 & 0,713 & 0,741 \\
\hline 2006 & 0,759 & 0,789 & 0,756 & 0,734 & 0,737 & 0,737 & 0,777 & 0,723 & 0,749 \\
\hline 2007 & 0,767 & 0,798 & 0,768 & 0,745 & 0,746 & 0,744 & 0,781 & 0,732 & 0,759 \\
\hline 2008 & 0,774 & 0,806 & 0,775 & 0,754 & 0,755 & 0,752 & 0,784 & 0,737 & 0,764 \\
\hline 2009 & 0,771 & 0,802 & 0,776 & 0,753 & 0,754 & 0,748 & 0,780 & 0,736 & 0,770 \\
\hline 2010 & 0,780 & 0,811 & 0,785 & 0,761 & 0,761 & 0,755 & 0,789 & 0,746 & 0,780 \\
\hline 2011 & 0,789 & 0,822 & 0,795 & 0,768 & 0,768 & 0,763 & 0,796 & 0,754 & 0,787 \\
\hline 2012 & 0,797 & 0,830 & 0,804 & 0,777 & 0,777 & 0,772 & 0,803 & 0,761 & 0,797 \\
\hline 2013 & 0,803 & 0,833 & 0,813 & 0,783 & 0,782 & 0,779 & 0,813 & 0,770 & 0,800 \\
\hline 2014 & 0,807 & 0,834 & 0,817 & 0,786 & 0,782 & 0,784 & 0,820 & 0,775 & 0,801 \\
\hline 2015 & 0,814 & 0,839 & 0,823 & 0,792 & 0,786 & 0,792 & 0,828 & 0,784 & 0,803 \\
\hline 2016 & 0,817 & 0,840 & 0,828 & 0,794 & 0,788 & 0,799 & 0,834 & 0,789 & 0,803 \\
\hline 2017 & 0,822 & 0,844 & 0,832 & 0,799 & 0,792 & 0,803 & 0,839 & 0,793 & 0,807 \\
\hline 2018 & 0,824 & 0,846 & 0,834 & 0,801 & 0,794 & 0,805 & 0,841 & 0,796 & 0,810 \\
\hline
\end{tabular}

Источник данных: База данных показателей HDI / Global Data Lab (База данных показателей HDI // Global Data Lab. URL: https://hdi.globaldatalab.org/areadata/shdi/ (дата обращения: 15.05.2020)).

Таблица 2

Отдельные компоненты ИЧР по федеральным округам РФ в 2018 гг.

Table 2

Individual HDI components by federal districts of the Russian Federation, 2018

\begin{tabular}{|l|c|c|c|c|c|}
\hline \multicolumn{1}{|c|}{ Регион } & $\begin{array}{c}\text { Логарифм от ВНД } \\
\text { на душу населения }\end{array}$ & $\begin{array}{c}\text { Ожидаемая продолжи- } \\
\text { тельность обучения (лет) }\end{array}$ & $\begin{array}{c}\text { Средняя продолжитель- } \\
\text { ность обучения (лет) }\end{array}$ & $\begin{array}{c}\text { ОПЖ } \\
\text { (лет) }\end{array}$ & $\begin{array}{c}\text { ИЧР } \\
\text { [ранг] }\end{array}$ \\
\hline Россия & 10,13 & 15,5 & 12,0 & 72,39 & 0,824 \\
\hline ЦФО & 10,41 & 15,7 & 12,1 & 73,59 & $0,846[1]$ \\
\hline СЗФО & 10,22 & 15,8 & 12,2 & 72,68 & $0,834[3]$ \\
\hline ЮФО & 9,68 & 15,4 & 11,9 & 72,81 & $0,801[6]$ \\
\hline СКФО & 9,10 & 16,1 & 12,5 & 75,67 & $0,794[8]$ \\
\hline ПФО & 9,80 & 15,6 & 12,1 & 71,90 & $0,805[5]$ \\
\hline УФО & 10,61 & 15,5 & 12,0 & 71,33 & $0,841[2]$ \\
\hline СФО & 9,92 & 15,1 & 11,7 & 70,31 & $0,796[7]$ \\
\hline ДФО & 10,37 & 14,9 & 11,5 & 69,72 & $0,810[4]$ \\
\hline СОВ(ИЧР) & 0,798 & 0,180 & 0,110 & $-0,003$ & 1 \\
\hline
\end{tabular}

Примечание: натуральный логарифм от показателя валового национального дохода (ВНД) на душу населения, измеренный в долларах США 2011 г. с учетом ППС.

Источник данных: База данных показателей HDI // Global Data Lab. URL: https://hdi.globaldatalab.org/areadata/shdi/ (дата обращения: 15.05.2020). 


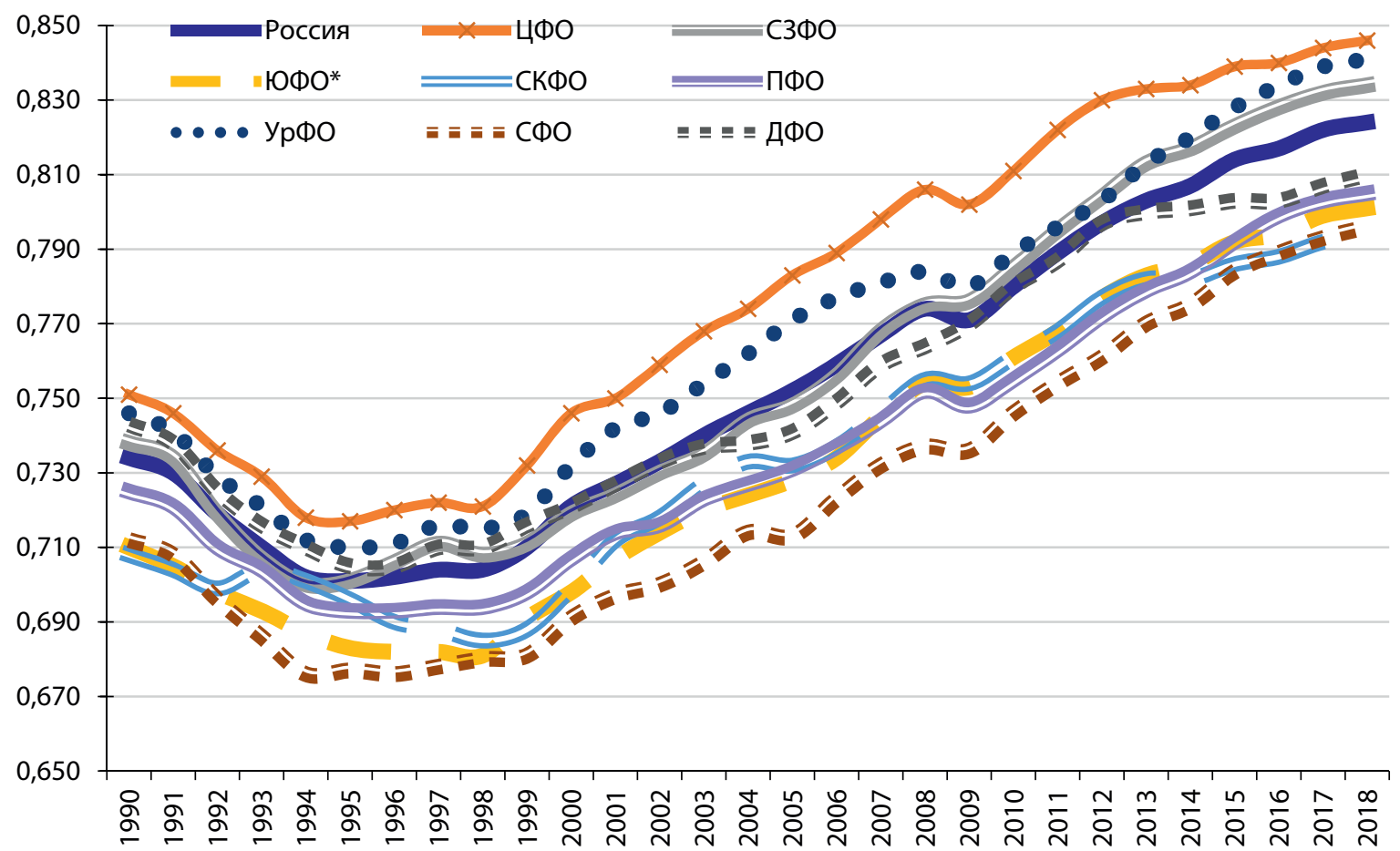

Рис. 1. Динамика значений ИЧР по федеральным округам РФ, 1990-2018 г2. (источник данных: База данных показателей HDI // Global Data Lab. URL: https://hdi.globaldatalab.org/areadata/shdi/(дата обращения: 15.05.2020))

FIg. 1. Dynamics of HDI values by federal districts of the Russian Federation, 1990-2018

валового дохода вносит дополнительные проблемы с оценкой ИЧР, так как ВНД является одновременно самой важной компонентой и самой сложной для оценивания и дальнейшего сопоставления. Мы видим, что агрегированный показатель благополучия людей, измеренный с помощью ожидаемой продолжительности жизни, оказывается не связан (коэффици- ент ранговой корреляция -0,003) с показателями ИЧР.

Используя методику оценки ИЧЖ, мы рассчитали значения ИЧЖ на уровне федеральных округов РФ (табл. 3, рис. 2).

Перейдем непосредственно к сопоставлению значений ИЧР и оценок ИЧЖ для федеральных округов РФ. Один из самых простых

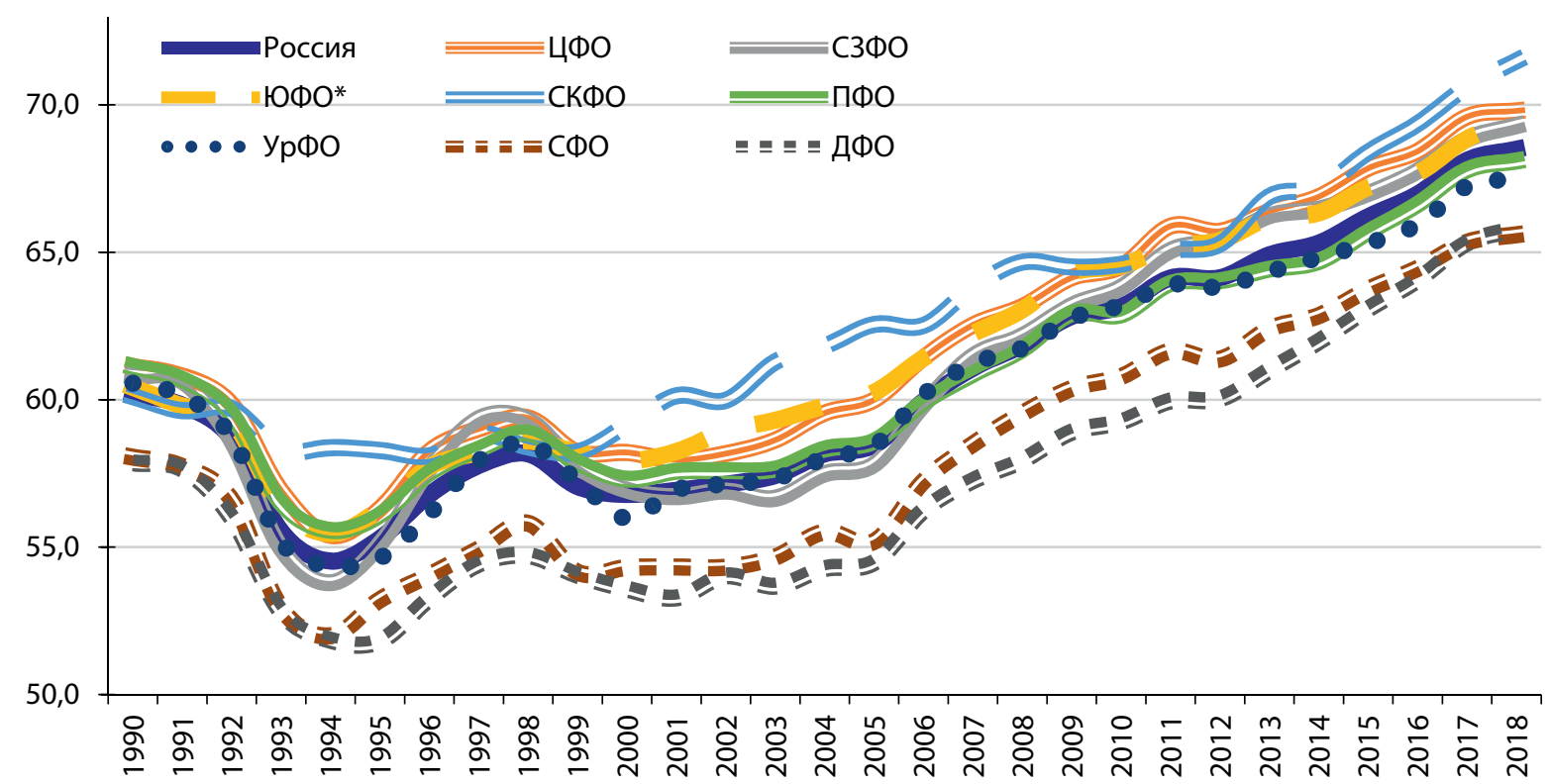

Рис. 2. Динамика значений ИЧЖ по федеральным округам РФ, 1990-2018 г2. (источник данных: авторские расчеты значений ИЧЖ)

Fig. 2. Dynamics of HLI values by federal districts of the Russian Federation, 1990-2018 
Таблица 3

Оценки ИЧЖ по федеральным округам РФ, 1990-2018 гг.

Table 3

HLI values by federal districts of the Russian Federation, 1990-2018

\begin{tabular}{|c|c|c|c|c|c|c|c|c|c|}
\hline \multirow{2}{*}{ Год } & ИЧЖ & \multicolumn{7}{|c|}{ Оценки ИЧЖ по федеральным округам } \\
\cline { 3 - 9 } & РФО & СЗФО & ЮФО & СКФО & ПФО & УрФО & СФО & ДФО \\
\hline 1990 & 60,2 & 61,1 & 60,8 & 60,4 & 60,1 & 61,1 & 60,6 & 58,1 & 57,9 \\
\hline 1991 & 59,8 & 60,8 & 60,6 & 59,8 & 59,6 & 60,7 & 60,1 & 57,7 & 57,6 \\
\hline 1992 & 58,7 & 59,9 & 58,6 & 59,3 & 59,7 & 59,5 & 58,7 & 56,6 & 56,0 \\
\hline 1993 & 55,5 & 56,9 & 55,0 & 56,3 & 58,3 & 56,5 & 55,2 & 52,9 & 52,8 \\
\hline 1994 & 54,5 & 55,4 & 53,8 & 55,5 & 58,4 & 55,6 & 54,4 & 52,0 & 51,8 \\
\hline 1995 & 55,3 & 56,3 & 55,1 & 56,3 & 58,3 & 56,1 & 54,6 & 53,2 & 51,8 \\
\hline 1996 & 56,8 & 58,2 & 57,7 & 57,7 & 58,1 & 57,5 & 56,1 & 54,1 & 53,2 \\
\hline 1997 & 57,8 & 59,0 & 59,4 & 58,2 & 58,9 & 58,3 & 57,9 & 54,9 & 54,4 \\
\hline 1998 & 58,2 & 59,4 & 59,3 & 58,6 & 58,4 & 58,9 & 58,5 & 55,8 & 54,7 \\
\hline 1999 & 57,1 & 58,2 & 57,7 & 58,2 & 58,2 & 57,9 & 57,2 & 54,1 & 54,0 \\
\hline 2000 & 56,8 & 58,2 & 56,9 & 57,9 & 59,1 & 57,3 & 56,0 & 54,3 & 53,6 \\
\hline 2001 & 56,9 & 58,0 & 56,7 & 58,2 & 60,1 & 57,6 & 56,9 & 54,3 & 53,3 \\
\hline 2002 & 57,1 & 58,2 & 56,9 & 59,0 & 60,0 & 57,6 & 57,1 & 54,3 & 54,0 \\
\hline 2003 & 57,4 & 58,6 & 56,7 & 59,3 & 61,3 & 57,6 & 57,3 & 54,7 & 53,7 \\
\hline 2004 & 58,2 & 59,5 & 57,5 & 59,8 & 61,8 & 58,3 & 58,0 & 55,5 & 54,3 \\
\hline 2005 & 58,5 & 60,0 & 57,8 & 60,3 & 62,6 & 58,6 & 58,4 & 55,2 & 54,5 \\
\hline 2006 & 59,9 & 61,4 & 59,8 & 61,4 & 62,5 & 59,9 & 60,2 & 57,2 & 56,2 \\
\hline 2007 & 61,1 & 62,5 & 61,5 & 62,3 & 63,8 & 60,9 & 61,2 & 58,5 & 57,3 \\
\hline 2008 & 61,8 & 63,2 & 62,2 & 63,1 & 64,7 & 61,7 & 61,8 & 59,5 & 57,9 \\
\hline 2009 & 62,8 & 64,1 & 63,2 & 64,3 & 64,5 & 62,9 & 62,8 & 60,4 & 58,9 \\
\hline 2010 & 63,2 & 64,5 & 63,8 & 64,5 & 64,6 & 62,9 & 63,2 & 60,8 & 59,3 \\
\hline 2011 & 64,1 & 65,9 & 65,1 & 65,2 & 65,1 & 63,9 & 63,9 & 61,7 & 60,0 \\
\hline 2012 & 64,1 & 65,7 & 65,4 & 65,4 & 65,3 & 64,0 & 63,8 & 61,4 & 60,0 \\
\hline 2013 & 64,9 & 66,4 & 66,2 & 66,2 & 66,9 & 64,4 & 64,3 & 62,4 & 61,0 \\
\hline 2014 & 65,3 & 66,9 & 66,5 & 66,3 & 67,2 & 64,7 & 64,8 & 62,9 & 62,0 \\
\hline 2015 & 66,2 & 67,9 & 67,0 & 67,2 & 68,4 & 65,7 & 65,3 & 63,8 & 63,1 \\
\hline 2016 & 67,0 & 68,4 & 67,8 & 67,7 & 69,4 & 66,6 & 65,9 & 64,5 & 64,1 \\
\hline 2017 & 68,1 & 69,6 & 68,8 & 68,9 & 70,6 & 67,8 & 67,2 & 65,3 & 65,3 \\
\hline 2018 & 68,5 & 69,8 & 69,3 & 69,5 & 71,5 & 68,1 & 67,5 & 65,6 & 65,8 \\
\hline
\end{tabular}

* Примечание: ЮФО с 1990 г. по 2015 г. рассчитан по данным показателей смертности в границах ЮФО действующих до 28 июля 2016 г.

Источник: авторские расчеты; данные по смертности для оценок таблиц смертности взяты из Российской базы данных по рождаемости и смертности (Российская база данных по рождаемости и смертности. Центр демографических исследований Российской экономической школы, Москва (Россия). URL: http://demogr.nes.ru/index.php/ru/demogr_indicat/data (дата обращения: 15.01.2020)).

способов понять, насколько они близки друг к другу - построить серию парных корреляций по округам РФ. Обратившись к этому методу, мы обнаруживаем, что значения двух индексов очень тесно коррелируют между собой во времени. Действительно, для каждого федерального округа коэффициент корреляции Пирсона между значениями ИЧР и ИЧЖ оказывается не ниже 0,93 , а в ряде случаев и заметно выше (табл. 4).

Поскольку для каждого округа брались значения за 1990-2018 гг., это означает, что дина- мика ИЧР и ИЧЖ была во многом синхронной. Это наглядно подтверждает сравнение рисунков 1 и 2.

Однако дальнейшее сравнение значений двух индексов выявляет весьма заметные различия, которые, на наш взгляд, имеют большое значение при оценке уровня человеческого развития того или иного округа. Для этого достаточно ранжировать федеральные округа по значению ИЧР (на первом месте - округа с наивысшим значением индекса, и т. д.), а затем провести аналогичное ранжи- 


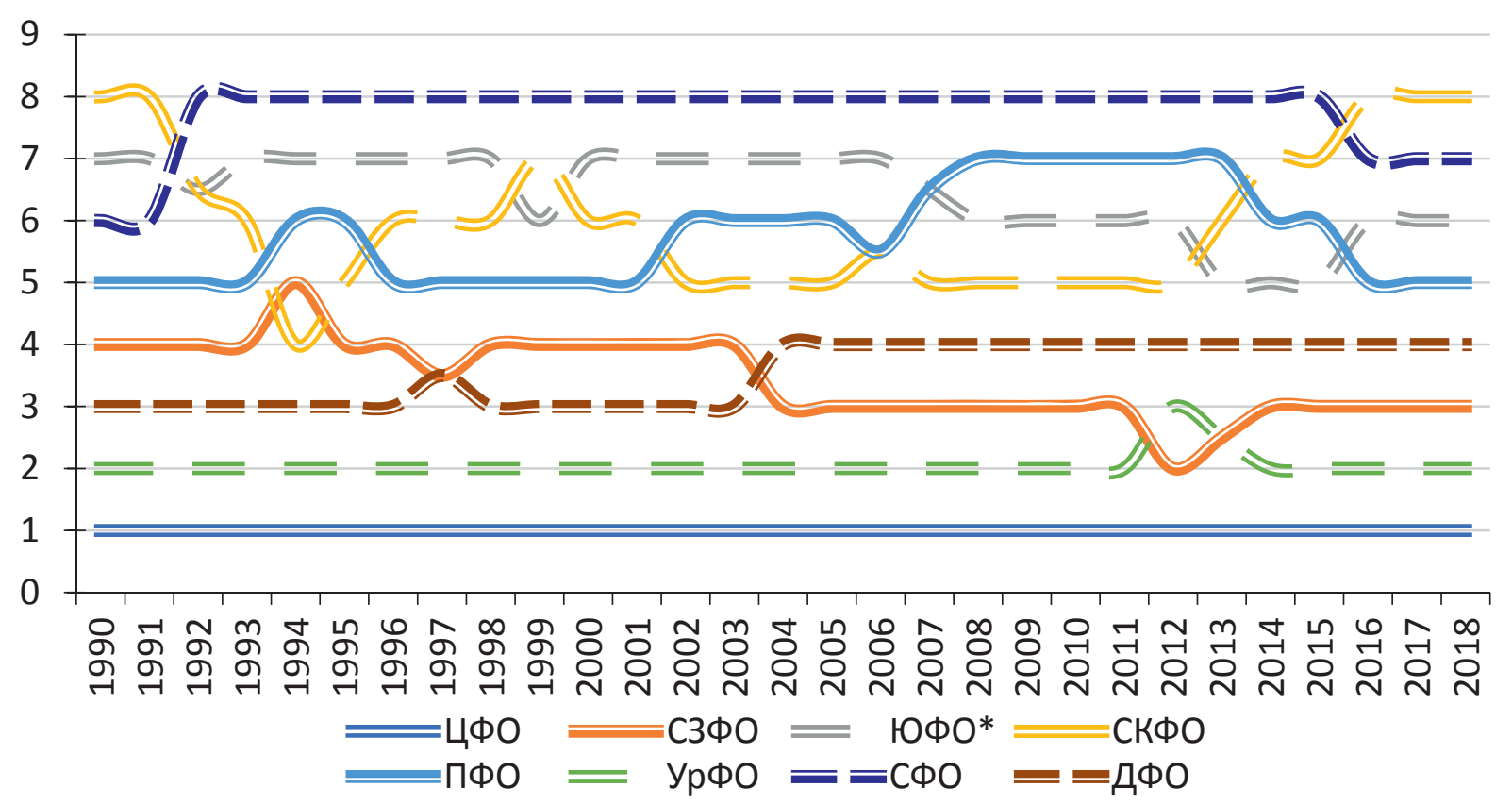

Рис. 3. Динамика ранжирования (мест в рейтинге) федеральных округов РФ относительно друг друга по ИЧР, 1990 2018 г2. (источник данных: расчеты по данным Базы данных показателей HDI // Global Data Lab [Электронный ресурс]. URL: https://hdi.globaldatalab.org/areadata/shdi/(дата обращения: 15.05.2020))

Fig. 3. Ranking dynamics (places in the rating) of the federal districts of the Russian Federation relative to each other according to HDI, 1990-2018

Таблица 4

Коэффициенты корреляции (Пирсона) между значениями ИЧР и ИЧЖ для отдельных федеральных округов

Table 4

Pearson correlation coefficients between HDI and HLI values for individual federal districts

\begin{tabular}{|c|c|}
\hline Регион & Значение коэффициента Пирсона \\
\hline Россия & 0,957 \\
\hline ЦФО & 0,938 \\
\hline СЗФО & 0,950 \\
\hline ЮФО & 0,974 \\
\hline СКФО & 0,977 \\
\hline ПФО & 0,954 \\
\hline УрФО & 0,939 \\
\hline СФО & 0,967 \\
\hline ДФО & 0,944 \\
\hline
\end{tabular}

Источник данных: авторские расчеты.

рование по ИЧЖ и сравнить места, полученные округами в этих двух рейтингах (рис. 3, 4 соответственно) ${ }^{1}$.

\footnotetext{
${ }^{1}$ На рисунке 3 в отдельных случаях наблюдаются значения мест в рейтинге, выраженные не целыми, а дробными числами. Например, в 2013 г. УрФО и СЗФО имеют место 2,5. Подобная ситуация означает, что в данный год абсолютные значения ИЧР этих двух округов оказались равными, и оснований поставить один из них на 2-е место, а другое на 3-е, у нас не было. Соответственно, такое значение следует трактовать как «два данных округа одновременное занимают 2-е и 3-е места в рейтинге»
}

Различия двух подходов становятся очевидными как при анализе группы округов-лидеров, так и при рассмотрении «аутсайдеров». Так, по показателю ИЧР бессменное первое место на протяжении всего рассматриваемого периода занимает Центральный федеральный округ; на втором месте почти всегда оказывается Уральский федеральный округ (кроме 2012 и 2013 гг., после которых округ вновь восстановил свои позиции). Дальневосточный федеральный округ опустился в первой половине 2000-х гг. с 3-го места на 4-е, в то время как Северо-Западный федеральный округ продемонстрировал «зеркальную» динамику, поднявшись с 4-го места на 3-е. Таким образом, верхняя половина рейтинга довольно стабильна, в отличие от нижней, где в течение рассматриваемого периода округа довольно часто меняли места в рейтинге. Следует отметить, что устойчивым «аутсайдером» на протяжении почти всего периода являлся Сибирский федеральный округ, который лишь в 2016 г. сумел подняться с последнего места на предпоследнее. Отметим тревожную отрицательную динамику в Северо-Кавказском федеральном округе, который с 5-го места, которое он занимал в 2012 г. (и на протяжении ряда лет до этого), упал до 8-го места в 2016 г.

Разительно отличающуюся картину рисует динамика ранжирования округов по ИЧЖ. Начиная с 1999 г., первое место занимает Северо- 


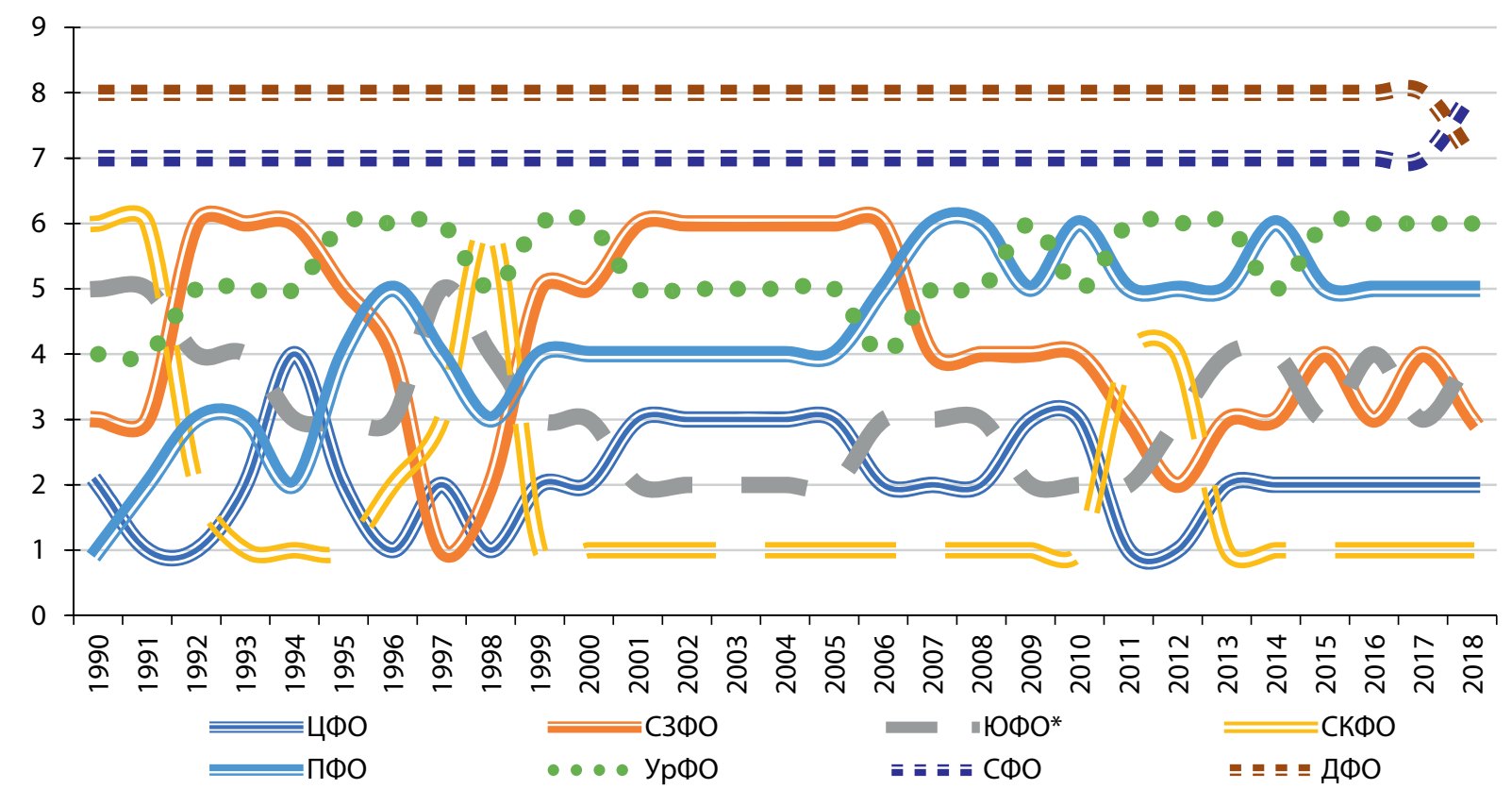

Рис. 4. Динамика ранжирования (мест в рейтинге) федеральных округов РФ относительно друг друга по ИЧЖ, 19902018 гг. (источник данных: авторские расчеты)

Fig. 4. Ranking dynamics (places in the rating) of the federal districts of the Russian Federation relative to each other according to HLI, 1990-2018

Кавказский федеральный округ (наблюдалось резкое падение до 4-го места в 2011-2012 гг., но уже к 2013 г. округ вновь занял лидирующую позицию). Центральный федеральный округ в основном колеблется между 2-м и 3-м местами, то есть ситуация здесь неплоха, но абсолютным и бессменным лидером (как в случае с ИЧР) он отнюдь не является. Тревожная тенденция наблюдается в Приволжском федеральном округе, занимавшем первое место в рейтинге в 1990 г.; к концу 1990-х гг. он скатился до 4-го места, на котором смог задержаться на какое-то время, после чего его падение продолжилось, и в последние годы он колеблется между 5-м и 6-м местами.

Особую тревогу вызывают Сибирский и Дальневосточный федеральные округа, являющиеся практически бессменными «аутсайдерами» по ИЧЖ (7-е и 8-е места соответственно). Если Сибирский округ занимает низкие позиции в обоих рейтингах, то столь низкое место Дальневосточного округа в рейтинге ИЧЖ, по всей видимости, как раз и вскрывает проблему, о которой говорили критики подхода ИЧР - высокое место в рейтинге ИЧР может быть обеспечено, к примеру, высоким ВРП, однако из-за неравенства он не трансформируется в улучшение качества жизни для большинства населения, вследствие чего сохраняются значительные разрывы по показателю ожидаемой продолжительности жизни (следует отметить, что в состав данного округа действительно входят регионы с весьма раз- личными показателями смертности и ОПЖ, однако и внутри самих регионов это неравенство выражено очень сильно (рис. 6)).

\section{Траектории дальнейшего роста показателей ИЧЖ}

Для оценки перспективной динамики ИЧЖ по России в целом и федеральным округам мы использовали нормативный сценарий, заложенный в показателях по ожидаемой продолжительности жизни в Указе Президента РФ от 07.05.2018 г. № 204, при котором ожидаемая продолжительность жизни в России быстро увеличивается до уровня 78 лет к 2024 г. и до уровня 80 лет к 2030 г. Оценки за 2018 г. мы брали исходя из общероссийского уровня ОПЖ в 2018 г. 73,1 года и сценария, предполагавшего, что в 2019 г. ОПЖ составит 73,4 года.

В сценарии заложена предпосылка долгосрочной (к 2051 г.) сходимости региональных половозрастных структур смертности к половозрастной структуре смертности Норвегии (с общей ОПЖ 81,5 лет), наблюдавшейся в 20102014 гг. по данным Human Mortality Database ${ }^{1}$.

На данной траектории показатель ИЧЖ для России существенно повышается до уровня 77 лет (как за счет роста ОПЖ, так и за счет су-

\footnotetext{
${ }^{1}$ Российская база данных по рождаемости и смертности. Центр демографических исследований Российской экономической школы, Москва (Россия). URL: http://demogr. nes.ru/index.php/ru/demogr_indicat/data (дата обращения: 15.01.2020)
} 
Прогнозные оценки ИЧЖ по федеральным округам РФ за 2019-2030 гг.

Таблица 5

Forecasted HLI values for federal districts of the Russian Federation, 2019-2030

Table 5

\begin{tabular}{|c|c|c|c|c|c|c|c|c|c|}
\hline \multirow{2}{*}{ Год } & \multirow{2}{*}{$\begin{array}{c}\text { ИЧЖ } \\
\text { Россия }\end{array}$} & \multicolumn{8}{|c|}{ Прогнозные оценки ИЧЖ по федеральным округам } \\
\hline & & ЦФО & СЗФО & ЮФО* & СКФО & ПФО & УрФО & СФО & ДФО \\
\hline 2019 & 68,7 & 70,1 & 69,4 & 69,4 & 70,8 & 68,4 & 67,9 & 66,4 & 66,1 \\
\hline 2020 & 69,8 & 71,0 & 70,4 & 70,3 & 71,7 & 69,4 & 69,0 & 67,7 & 67,3 \\
\hline 2021 & 70,9 & 72,0 & 71,4 & 71,4 & 72,6 & 70,6 & 70,2 & 69,0 & 68,6 \\
\hline 2022 & 72,0 & 73,0 & 72,5 & 72,4 & 73,5 & 71,7 & 71,4 & 70,4 & 70,0 \\
\hline 2023 & 73,2 & 74,0 & 73,6 & 73,6 & 74,5 & 73,0 & 72,7 & 71,8 & 71,5 \\
\hline 2024 & 74,5 & 75,1 & 74,8 & 74,7 & 75,5 & 74,3 & 74,1 & 73,3 & 73,1 \\
\hline 2025 & 74,9 & 75,5 & 75,1 & 75,1 & 75,8 & 74,7 & 74,5 & 73,8 & 73,6 \\
\hline 2026 & 75,3 & 75,8 & 75,5 & 75,5 & 76,2 & 75,1 & 75,0 & 74,4 & 74,1 \\
\hline 2027 & 75,7 & 76,2 & 75,9 & 75,9 & 76,5 & 75,6 & 75,4 & 74,9 & 74,7 \\
\hline 2028 & 76,2 & 76,6 & 76,3 & 76,3 & 76,8 & 76,0 & 75,9 & 75,4 & 75,2 \\
\hline 2029 & 76,6 & 76,9 & 76,7 & 76,7 & 77,2 & 76,5 & 76,4 & 76,0 & 75,8 \\
\hline 2030 & 77,0 & 77,3 & 77,2 & 77,2 & 77,5 & 76,9 & 76,8 & 76,5 & 76,4 \\
\hline
\end{tabular}

Источник данных: авторские расчеты.

щественного сокращения неравенства в смертности), при этом ускоренными темпами сокращается избыточная сверхсмертность в трудоспособных возрастах, что приводит к дополнительному вкладу в увеличение ИЧЖ (помимо роста продолжительности жизни).

Относительное положение федеральных округов не изменяется при предпосылке долгосрочной сходимости. Даже при условии оп- тимистичной долгосрочной сходимости между федеральными округами остаются различия в данном показателе, хотя эти масштаб этих различий сокращается по сравнению с текущей ситуацией (табл. 5, рис. 5).

\section{Выводы}

Таким образом, использование нового демографического индикатора - индекса человече-

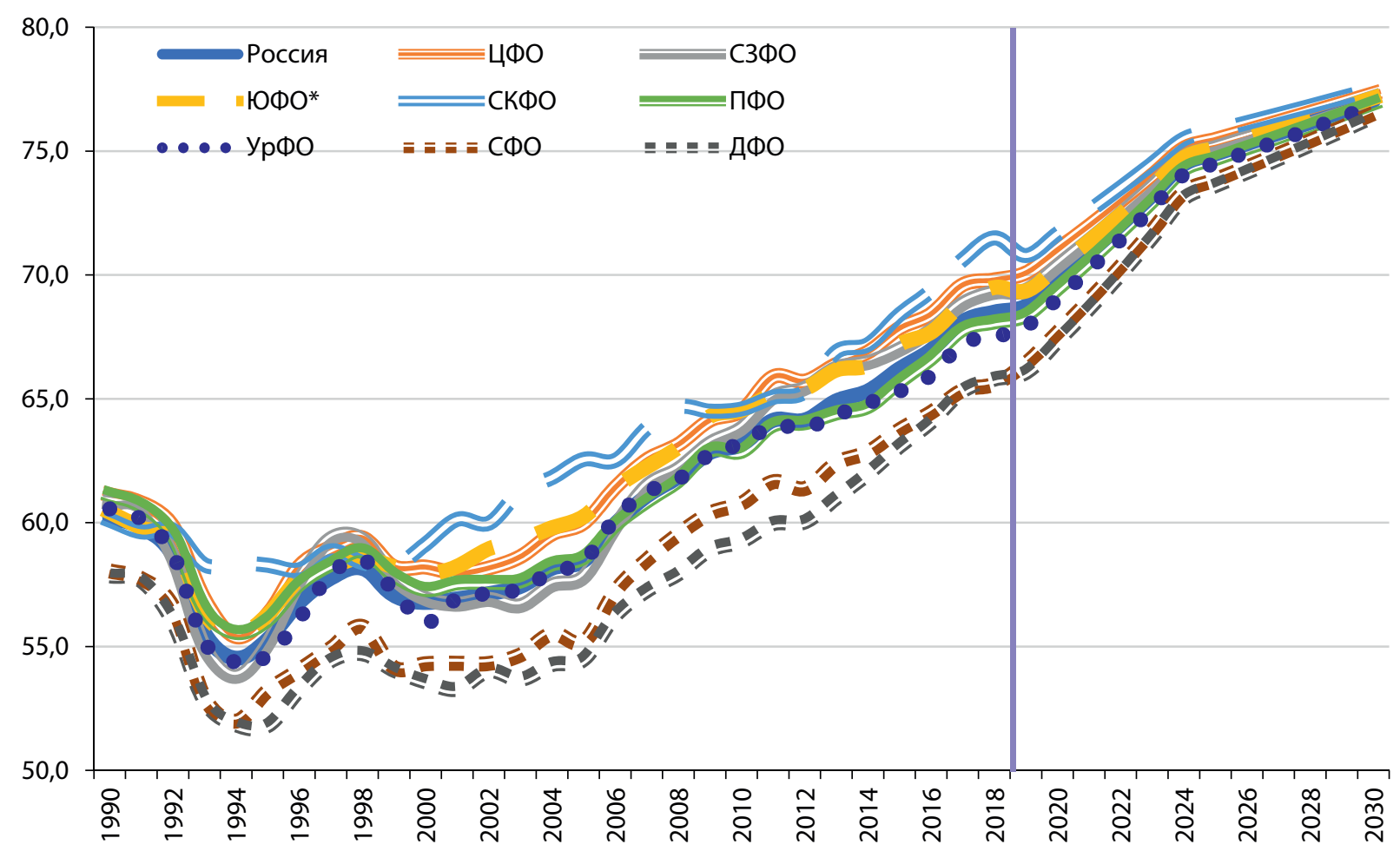

Рис. 5. Динамика значений ИЧЖ по федеральным округам РФ, 1990-2018 г2. и прогнозные оченки ИЧЖ по федеральным округам РФ за 2019-2030 г2.

Fig. 5. Dynamics of HLI values by federal districts of the Russian Federation, 1990-2018, and forecasted HLI values by federal districts of the Russian Federation, 2019-2030 


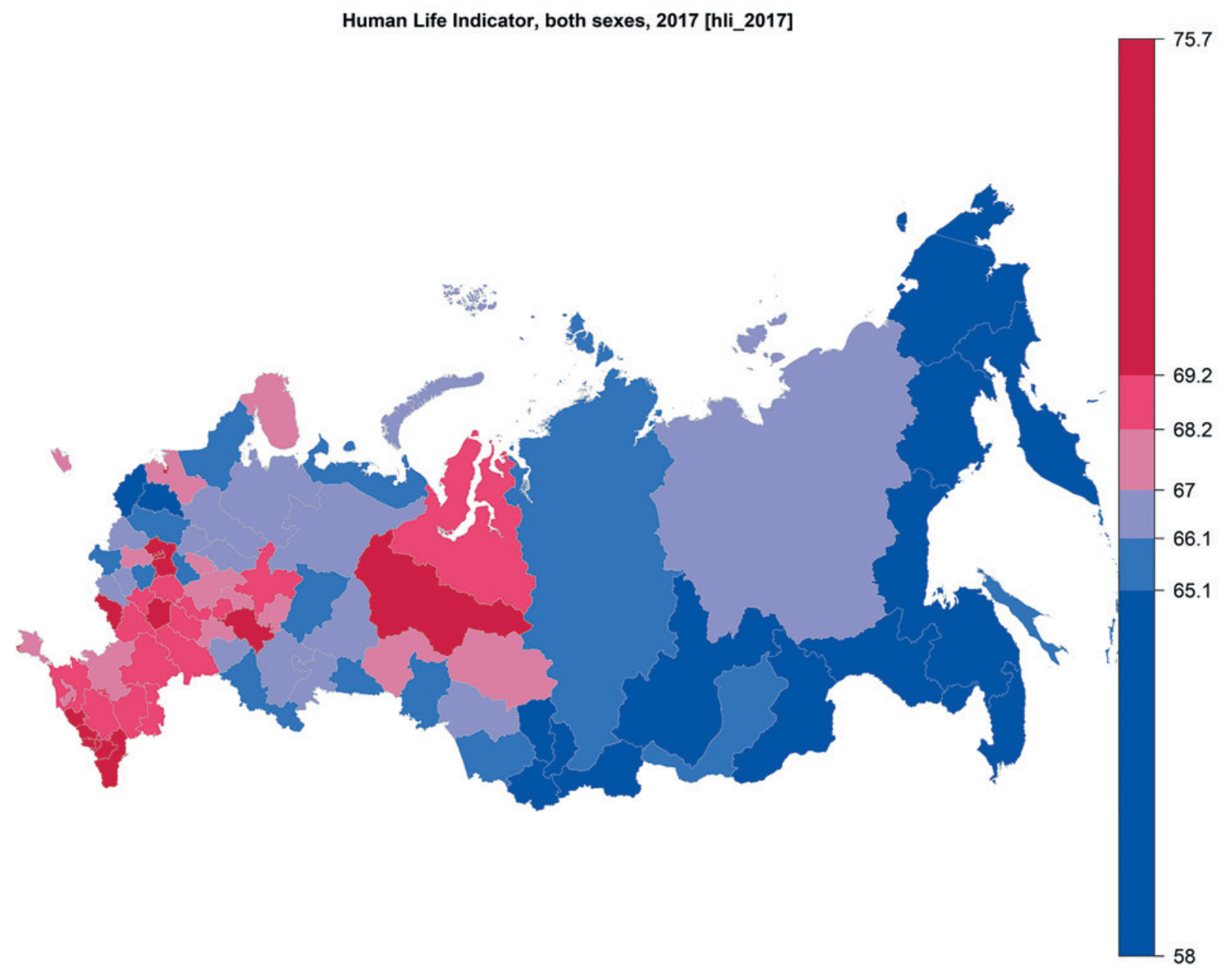

Рис. 6. Значения ИЧЖ по регионам РФ, 2017 г. (источник данных: [26])

Fig. 6. HLI values by regions of the Russian Federation, 2017

ской жизни - для оценки уровня человеческого развития федеральных округов России и сопоставление оценок, рассчитанных по методике ИЧЖ, со значениями ИЧР для федеральных округов за аналогичный период дало целый ряд интересных результатов. В частности, выявлен наглядный пример, поддерживающий один их наиболее существенных пунктов критики подхода ИЧР - высокое место в рейтинге ИЧР может быть обеспечено, к примеру, высоким ВРП, однако из-за высокого неравенства даже значительный доход региона не трансформируется в улучшение качества жизни для большинства населения ${ }^{1}$, вследствие чего сохраняются значительные разрывы по показателю ожидаемой продолжительности жизни. Более того, подобная ситуация наблюдается не только на уровне федеральных округов (в состав которых могут входить регионы с изначально весьма различными показателями смертности и ОПЖ), но и на уровне самих регионов (рис. 6.)

\footnotetext{
${ }^{1}$ В России это может свидетельствовать еще и о несовершенстве механизма бюджетных трансфертов.
}

На рисунке 6 видно, что благополучные и относительно благополучные по ИЧЖ регионы концентрируются в европейской части России. При этом доход региона не является однозначным предиктором низкого уровня неравенства в показателях смертности и ОПЖ среди населения - так, Республика Ингушетия имеет более высокий ИЧЖ, чем Москва и Санкт-Петербург. Однозначно требует внимания федеральных и региональных властей ситуация в большинстве регионов Сибири и Дальнего Востока, где сложилось очень высокое неравенство по ОПЖ, и ситуация явно требует вмешательства и корректировки при помощи конкретных мер (в том числе борьбы с отдельными причинами смертности, вносящими наибольший вклад в это неравенство в данных регионах).

В целом представляется, что применение методики ИЧЖ для оценки уровня человеческого развития федеральных округов и регионов России является весьма перспективным, поскольку позволяет взглянуть на этот уровень под новым углом и выявить важные проблемные аспекты, связанные с неравенством (в том 
числе неравенством в ОПЖ) и региональными доходами, которые «маскируются» в других подходах, в частности, ИЧР. Соответственно, хотя ИЧР на настоящее время остается признанной на международном уровне и часто используемой методикой, представляется целесообразным дополнить ее как минимум в России при анализе состояния человече- ского развития в округах и регионах оценками ИЧЖ. В перспективе ИЧЖ может использоваться и на международном уровне для сравнения стран - в том числе для сопоставления различных систем здравоохранения в аспекте их влияния на сокращение или увеличение неравенства в продолжительности жизни среди населения.

\section{Список источников}

1. Мау В. А. Человеческий капитал. Вызовы для России // Вопросы экономики. 2012. № 7. С. 114-132.

2. Mincer J. Investment in human capital and personal income distribution // Journal of political economy. 1958. Vol. 66, №. 4. C. 281-302. DOI: 10.1086/258055.

3. Schultz T. W. Investment in human capital // The American economic review. 51(1). 1961. C. 1-17.

4. Becker G. S. Human capital. New York: Columbia University Press, 1964. 187 p.

5. Human Development Report 1990. United Nations Development Programme. New York, 1990. 141 p.

6. Human Development Report 2019. Beyond income, beyond averages, beyond today: Inequalities in human development in the 21st century. United Nations Development Programme. New York, 2019. 366 p.

7. Ghislandi S., Sanderson W. C., Scherbov S. A Simple Measure of Human Development: The Human Life Indicator // Population and Development Review. 2019. Vol. 45 (1). P. 219-233. DOI: 10.1111/padr.12205.

8. Klugman J., Rodríguez F., Choi H.J. The HDI 2010: new controversies, old critiques // The Journal of Economic Inequality. 2011. Vol. 9, №. 2. P. 249-288. DOI: 10.1007/s10888-011-9178-Z.

9. McGillivray $M$. The human development index: yet another redundant composite development indicator? // World Development. 1991. Vol. 19, №. 10. P. 1461-1468. DOI: 10.1016/0305-750X(91)90088-Y.

10. McGillivray M., White H. Measuring development? The UNDP's human development index // Journal of international development. 1993. Vol. 5, №. 2. P. 183-192. DOI: 10.1002/jid.3380050210.

11. Beyond GDP: Measuring and achieving global genuine progress / Kubiszewski I., Costanza R., Franco C., Lawn P., Talberth J., Jackson T., Aylmer C. // Ecological economics. 2013. Vol. 93. P. 57-68. DOI: 10.1016/j.ecolecon.2013.04.019.

12. Noorbakhsh F. A modified human development index // World Development. 1998. Vol. 26, №. 3. P. 517-528. DOI: 10.1016/S0305-750X(97)10063-8.

13. Sagar A.D., Najam A. The human development index: a critical review // Ecological economics. 1998. Vol. 25 , №. 3. P. 249-264. DOI: 10.1016/S0921-8009(97)00168-7.

14. Ranis G., Stewart F., Samman E. Human development: beyond the human development index // Journal of Human Development. 2006. Vol. 7, №. 3. P. 323-358. DOI: 10.1080/14649880600815917.

15. Booysen F. An overview and evaluation of composite indices of development // Social indicators research. 2002. Vol. 59, №. 2. P. 115-151. [DOI: 10.1023/A:1016275505152.

16. Bérenger V., Verdier-Chouchane A. Multidimensional measures of well-being: Standard of living and quality of life across countries // World Development. 2007. Vol. 35, №. 7. P. 1259-1276. DOI: 10.1016/j.worlddev.2006.10.011.

17. Noorbakhsh F. The human development index: some technical issues and alternative indices // Journal of International Development: The Journal of the Development Studies Association. 1998. Vol. 10, №. 5. P. 589-605. DOI: 10.1002/ (SICI)1099-1328(199807/08)10:5<589::AID-JID484>3.0.CO;2-S.

18. Hicks D. A. The inequality-adjusted human development index: a constructive proposal // World development. 1997. Vol. 25, №. 8. P. 1283-1298. DOI: 10.1016/S0305-750X(97)00034-X.

19. Alkire S., Foster J.E. Designing the inequality-adjusted human development index. Oxford Poverty \& Human Development Initiative. Working Paper. 2010. No 37. DOI: 10.2139/ssrn.1815248.

20. Grimm M., Harttgen K., Klasen S., Misselhorn M. A human development index by income groups // World Development. 2008. Vol. 36, №. 12. P. 2527-2546. DOI: 10.1016/j.worlddev.2007.12.001.

21. Inequality in human development: An empirical assessment of 32 countries / Grimm M., Harttgen K., Klasen S., Misselhorn M., Munzi T., Smeeding T. // Social Indicators Research. 2010. Vol. 97, №. 2. P. 191-211. DOI: 10.1007/s11205009-9497-7.

22. Harttgen K., Klasen S. A household-based human development index // World Development. 2012. Vol. 40, №. 5. C. 878-899. DOI: 10.1016/j.worlddev.2011.09.011.

23. Pillarisetti J.R. An empirical note on inequality in the world development indicators // Applied Economics Letters. 1997. Vol. 4, №. 3. C. 145-147. DOI: 10.1080/135048597355393.

24. Sanderson W. C., Scherbov S. Prospective Longevity: A New Vision of Population Aging. Harvard University Press, 2019. 272 p. DOI: 10.4159/9780674243316.

25. Andreev E. M., Kingkade W. W. Average age at death in infancy and infant mortality level: Reconsidering the CoaleDemeny formulas at current levels of low mortality // Demographic Research. 2015. Vol. 33. P. 363-390. DOI: 10.4054/ DemRes.2015.33.13. 
26. Регионы России на демографической карте мира. Москва; Лаксенбург : Российская академия народного хозяйства и государственной службы, Издательство «Дело»; Международный Институт Прикладного Системного Анализа, 2019. 98 с.

\section{References}

1. Mau, V. A. (2012). Human capital: challenges for Russia. Voprosy ekonomiki, 7, 114-132. (In Russ.)

2. Mincer, J. (1958). Investment in human capital and personal income distribution. Journal of political economy, 66(4), 281-302. DOI: $10.1086 / 258055$

3. Schultz, T. W. (1961). Investment in human capital. The American economic review, 51(1), 1-17.

4. Becker, G. S. (1964). Human capital. New York : Columbia University Press, 187.

5. UNDP. (1990). Human Development Report 1990. United Nations Development Programme, New York, 141.

6. UNDP. (2019). Human Development Report 2019. Beyond income, beyond averages, beyond today: Inequalities in human development in the 21st century. United Nations Development Programme, New York, 366.

7. Ghislandi, S., Sanderson, W. C. \& Scherbov, S. (2019). A Simple Measure of Human Development: The Human Life Indicator. Population and Development Review, 45(1), 219-233. DOI: 10.1111/padr.12205.

8. Klugman, J., Rodríguez, F. \& Choi, H. J. (2011). The HDI 2010: new controversies, old critiques. The Journal of Economic Inequality, 9(2), 249-288. DOI: 10.1007/s10888-011-9178-z.

9. McGillivray, M. (1991). The human development index: yet another redundant composite development indicator? World Development, 19(10), 1461-1468. DOI: 10.1016/0305-750X(91)90088-Y.

10. McGillivray, M. \& White, H. (1993). Measuring development? The UNDP's human development index. Journal of International Development, 5(2), 183-192. DOI: 10.1002/jid.3380050210.

11. Kubiszewski, I., Costanza, R., Franco, C., Lawn, P., Talberth, J., Jackson, T. \& Aylmer. C. (2013). Beyond GDP: Measuring and achieving global genuine progress. Ecological Economics, 93, 57-68. DOI: 10.1016/j.ecolecon.2013.04.019.

12. Noorbakhsh. F. (1998). A modified human development index. World Development, 26(3), 517-528. DOI: 10.1016/ S0305-750X(97)10063-8.

13. Sagar, A. D. \& Najam, A. (1998). The human development index: a critical review. Ecological Economics, 25(3), 249-264. DOI: 10.1016/S0921-8009(97)00168-7.

14. Ranis, G., Stewart, F. \& Samman, E. (2006). Human development: beyond the human development index. Journal of Human Development, 7(3), 323-358. DOI: 10.1080/14649880600815917.

15. Booysen, F. (2002). An overview and evaluation of composite indices of development. Social Indicators Research, 59(2), 115-151. DOI: 10.1023/A:1016275505152.

16. Bérenger, V. \& Verdier-Chouchane, A. (2007). Multidimensional measures of well-being: Standard of living and quality of life across countries. World Development, 35(7), 1259-1276. DOI: 10.1016/j.worlddev.2006.10.011.

17. Noorbakhsh, F. (1998). The human development index: some technical issues and alternative indices. Journal of International Development, 10(5), 589-605. DOI: 10.1002/(SICI)1099-1328(199807/08)10:5<589::AID-JID484>3.0.CO;2-S.

18. Hicks, D. A. (1997). The inequality-adjusted human development index: a constructive proposal. World Development, 25(8), 1283-1298. DOI: 10.1016/S0305-750X(97)00034-X.

19. Alkire, S. \& Foster, J. E. (2010). Designing the inequality-adjusted human development index. Oxford Poverty \& Human Development Initiative. OPHI Working Paper No 37. DOI: 10.2139/ssrn.1815248.

20. Grimm, M., Harttgen, K., Klasen, S. \& Misselhorn, M. (2008). A human development index by income groups. World Development, 36(12), 2527-2546. DOI: 10.1016/j.worlddev.2007.12.001.

21. Grimm, M., Harttgen, K., Klasen, S., Misselhorn, M., Munzi, T. \& Smeeding, T. (2010). Inequality in human development: An empirical assessment of 32 countries. Social Indicators Research, 97(2), 191-211. DOI: 10.1007/s11205-0099497-7.

22. Harttgen, K. \& Klasen, S. (2012). A household-based human development index. World Development, 40(5), 878899. DOI: 10.1016/j.worlddev.2011.09.011.

23. Pillarisetti, J. R. (1997). An empirical note on inequality in the world development indicators. Applied Economics Letters, 4(3), 145-147. DOI: 10.1080/135048597355393.

24. Sanderson, W. C. \& Scherbov, S. (2019). Prospective Longevity: A New Vision of Population Aging. Harvard University Press, 272. DOI: 10.4159/9780674243316.

25. Andreev, E. M. \& Kingkade, W.W. (2015). Average age at death in infancy and infant mortality level: Reconsidering the Coale-Demeny formulas at current levels of low mortality. Demographic Research, 33, 363-390. DOI: 10.4054/ DemRes.2015.33.13.

26. Regiony Rossii na demograficheskoy karte mira [Russian regions on the world demographic map]. (2019). Moscow: Russian Presidential Academy of National Economy and Public Administration, Publishing House Delo. Laxenburg, Austria: International Institute for Applied Systems Analysis (IIASA), 98. (In Russ.)

\section{Информация об авторах}

Шульгин Сергей Георгиевич - кандидат экономических наук, заместитель заведующего Международной лаборатории демографии и человеческого капитала Российской академии народного хозяйства и государствен- 
ной службы при Президенте РФ; https://orcid.org/0000-0003-1091-7157 (Российская Федерация, 119571, Москва, Проспект Вернадского, 82; e-mail: sergey@shulgin.ru).

Зинькина Юлия Викторовна - кандидат исторических наук, старший научный сотрудник РАНХиГС, преподаватель факультета глобальных процессов Московского государственного университета имени М. В. Ломоносова; https://orcid.org/0000-0003-0524-2140 (Российская Федерация, 119234, Москва, Ленинские горы, 1; e-mail: juliazin@ list.ru).

\section{About the authors}

Sergey G. Shulgin - Cand. Sci. (Econ.), Deputy Head of the International Research Laboratory for Demography and Human Capital, Russian Presidential Academy of National Economy and Public Administration; https://orcid.org/00000003-1091-7157 (82, Vernadskogo Ave., Moscow, 119571, Russian Federation; e-mail: sergey@shulgin.ru).

Yulia V. Zinkina - Cand. Sci. (Hist.), Senior Research Associate, Russian Presidential Academy of National Economy and Public Administration; Lecturer, Faculty of Global Studies, Lomonosov Moscow State University; https://orcid. org/0000-0003-0524-2140 (1, Leninskie gory, Moscow, 119234, Russian Federation; e-mail: juliazin@list.ru).

Дата поступления рукописи: 05.02.2020.

Прошла рецензирование: 15.05.2020.

Принято решение о публикации: 18.06.2021.

Received: 5 Feb 2020.

Reviewed: 15 May 2020.

Accepted: 18 Jun 2021. 